\title{
TIPOLOGI MOTIF TELAPAK TANGAN DI SITUS GUA ANAWAI, KABUPATEN KONAWE UTARA PROVINSI SULAWESI TENGGARA
}

\author{
(Typology Handstancil Motive in Cave Anawai Site, North Konawe Regency, \\ Provience Sulawesi Tenggara)
}

Syahrun, M. Sabri, dan Sandy Suseno, Jurusan Arkeologi Fakultas Ilmu Budaya Universitas Halu Oleo Pos-el : syahrun antro@yahoo.com, Sabriark014uho11@gmail.com, suseno.sandy@gmail.com

\begin{tabular}{|c|c|}
\hline INFO ARTIKEL & ABSTRACT \\
\hline $\begin{array}{l}\text { Histori Artikel } \\
\text { Diterima : 11 Januari } 2021 \\
\text { Direvisi : } 19 \text { Maret } 2021 \\
\text { Disetujui : } 8 \text { April } 2021 \\
\end{array}$ & $\begin{array}{l}\text { This research was conducted at Anawai Cave Site, located in } \\
\text { Bendewuta Village, Oheo District, North Konawe Regency, } \\
\text { Southeast Sulawesi Province. This study aims to determine the } \\
\text { typology of handprint motifs in the Anawai Cave Site. The }\end{array}$ \\
\hline $\begin{array}{l}\text { Keywords: } \\
\text { rock arts; hand stencil } \\
\text { motives; typology of } \\
\text { motives } \\
\text { Kata kunci: } \\
\text { gambar cadas; motif } \\
\text { cap tangan; tipologi } \\
\text { motif }\end{array}$ & $\begin{array}{l}\text { primary data collection method was carried out by field } \\
\text { observations by making a site location map, recording rock } \\
\text { image data. The map of this site location was processed with } \\
\text { the Geographic Information System (GIS) method and using of } \\
\text { ArcMap 10.7. Besides, The rock art images are processed } \\
\text { using the Image J and Adobe Illustrator software to sharpen } \\
\text { the colors of the mages that have been damaged. Data were } \\
\text { classified using taxonomic methods to produce a typology of } \\
\text { handprint motifs. The results showed that the most dominant } \\
\text { form of hand stamp motifs was the hand stamp without wrist } \\
\text { or arm. }\end{array}$ \\
\hline
\end{tabular}

\begin{abstract}
ABSTRAK
Penelitian ini dilakukan di Situs Gua Anawai yang terletak di Desa Bendewuta, Kecamatan Oheo, Kabupaten Konawe Utara, Provinsi Sulawesi Tenggara. Penelitian ini bertujuan untuk mengetahui tipologi motif cap tangan di Situs Gua Anawai. Metode pengumpulan data primer dilakukan dengan observasi lapangan dengan melakukan pembuatan peta lokasi situs, perekaman data gambar cadas. Peta lokasi situs diolah menggunakan metode Geographic Information System (GIS) dengan memanfaatkan software ArcMap 10.7 dan gambar cadas diolah menggunakan Image $\mathrm{J}$ dan Adobe Illustrator untuk mempertajam warna gambar yang telah mengalami kerusakan parah. Selanjutnya data diklasifikasikan menggunakan metode taksonomi untuk menghasilkan tipologi motif cap tangan. Hasil penelitian menunjukkan bahwa bentuk motif cap tangan yang paling mendominasi adalah motif cap tangan tanpa pergelangan maupun lengan.
\end{abstract}




\section{PENDAHULUAN}

Wilayah Sulawesi bagian Tenggara merupakan wilayah yang terletak di dalam kawasan geografis Wallacea. Penyebutan kawasan Wallacea merujuk pada wilayah di daerah Indonesia bagian tengah. Wilayah ini merupakan sebuah kawasan transisi yang tidak pernah terhubung oleh jembatan darat. Hal ini menyebabkan, wilayah ini memiliki kesatuan lingkungan, flora, dan fauna yang khas. Diketahui pula bahwa kolonisasi awal penutur Austronesia di kawasan Wallacea telah berkembang sejak 3600 B.P. Tetapi, saat penutur austronesia datang kawasan Wallacea, kawasan ini bukanlah suatu daerah kosong. Populasi Austro-Melanesid yang kini menempati daratan Papua dan Australia yang berasal dari Asia Tenggara Daratan juga pernah menempati kawasan Wallacea sebelum kedatangan penutur Austronesia di wilayah ini (Noerwidi; 2008:3; 2014: 2). Oleh karena itu, tidak mengherankan bahwa di wilayah Sulawesi Tenggara yang juga merupakan bagian dari kawasan
Wallacea menyimpan tinggalantinggalan arkeologi dari masa prasejarah yang sangat banyak. Hal tersebut dibuktikan dengan kehadiran berbagai situs-situs gua prasejarah yang tersebar di beberapa wilayahnya. Salah satu tinggalan arkeologis yang kerap ditemukan dalam situs-situs gua tersebut adalah gambar cadas (rock art). Gambar cadas secara sederhana diartikan sebagai gambar, motif, dan desain yang ditempatkan pada permukaan batuan alami seperti permukaan tebing dan batuan, dinding, langitlangit, dan permukaan dasar gua (Whitley, 2005: 3). Di antara motifmotif gambar cadas yang kerap digambarkan yaitu motif manusia, hewan, tumbuhan, benda budaya, objek geometris dan objek abstrak.

Situs-situs gua dengan tinggalan berupa gambar cadas di Sulawesi Tenggara umumnya tersebar di wilayah pedalam semisal di Kabupaten Konawe, Konawe Utara, Muna, dan di wilayah pesisir sebagaimana yang ditemukan di Kabupaten Buton Selatan (Oktaviana (2016); Mulyadi (2016); Nipa (2018); 
Usman (2019). Selain Kabupaten Muna yang diketahui memiliki situs gua dengan jumlah yang cukup banyak, Kabupaten Konawe Utara kemudian deketahui pula memiliki situs-situs gua dengan tinggalan berupa gambar cadas dengan jumlah yang cukup banyak. Salah satu di antara situs-situs tersebut yaitu Situs Gua Anawai. Saat ini situs tersebut merupakan satu-satunya situs dengan gambar cadas di Kabupaten Konawe Utara dengan tinggalan arkeologi berupa gambar cadas dengan cap tangan yang telah ditemukan. Beberapa peneliti pun telah melaporkan situs tersebut misalnya oleh Luc Henri Fage (2014) dan Nur dan Duli (2017). Dari laporan tersebut diketahui bahwa gambar cadas dengan motif cap tangan di situs tersebut memiliki jumlah yang cukup banyak dan menampakkan variasi dari bentuknya. Meskipun demikian, terdapat perbedaan informasi mengenai keseluruhan motif cap tangan yang terdapat di Situs Gua Anawai berdasarkan kedua laporan tersebut.

Berdasarkan hal tersebut, maka perlu dilakukan studi terkait tinggalan arkeologis tersebut terkhusus untuk gambar cadas motif telapak tangan untuk mengetahui tipologi bentuk motif cap tangan dari situs tersebut.

Berdasarkan latar belakang di atas maka rumusan masalah dalam penelitian ini yaitu:

1. Bagaimana tipologi bentuk motif cap tangan di Situs Gua Anawai?

2. Bagaimana teknologi pembuatan motif cap tangan di Situs Gua Anawai?

Penelitian mengenai Gambar Cadas dengan dengan motif cap tangan telah banyak dilakukan oleh para arkeolog yang tertarik dengan tema gambar cadas. Penelitianpenelitian tersebut sangat bervariatif, dari yang bersifat deskriptif hingga upaya untuk memahami makna dari gambar cadas tersebut. Diantara penelitian-penelitian tersebut misalnya yang dilakukan oleh Permana (2014) melakukan penelitian mengenai bentuk gambar telapak tangan pada gua-gua prasejarah di Kabupaten Pangkajene Kepulauan dan Maros. Hasil penelitian tersebut menunjukkan bahwa gambar telapak tangan yang 
ditemukan didominasi oleh gambar telapak tangan tanpa pergelangan tangan atau lengan, gambar telapak tangan yang memiliki lima jari, gambar telapak tangan yang berukuran besar, gambar telapak tangan yang berorientasi ke atas dan gambar telapak tangan yang berwarna cokelat (Permana, 2014: 286). Perbedaan penelitian tersebut dengan penelitian ini adalah pada aspek lokasi penelitian.

Selanjutnya, terdapat penelitian yang dilakukan oleh Leihitu (2016) mengenai tipologi motif cap tangan prasejarah di Leang Uhallie, Kabupaten Bone, Sulawesi Selatan, Hasil penelitian tersebut menunjukkan bahwa terdapat tiga bentuk motif cap tangan yaitu motif telapak tangan, telapak sampai pergelangan, dan telapak sampai lengan. Adapun di Wilayah Sulawesi Tenggara daratan penelitian mengenai gambar telapak tangan telah dilakukan oleh Oktaviana, dkk (2016) di Situs Gua Andomo dan Gua Lampetia yang menunjukkan bahwa mayoritas motif cap tangan dari kedua situs tersebut dibuat dengan pigmen berwarna merah dan sisanya dari pigmen berwarna hitam. Selanjutnya pada motif cap tangan berwarna merah beberapa diantaranya ditemukan dengan bentuk jari yang mengalami penyempitan (Oktaviana, dkk. 2016: 32). Perbedaan penelitian tersebut dengan penelitian ini yaitu penulis penulis terfokus untuk melihat bentuk keseluruhan dari cap tangan yang ditemukan.

Lokasi penelitian ini dilakukan pada situs Gua Anawai yang terletak di Desa Bendewuta, Kecamatan Oheo, Kabupaten Konawe Utara. Data dalam penelitian ini terdiri atas data primer dan data sekunder. Data primer yang dimaksudkan berupa data yang diperoleh melalui observasi secara langsung terhadap objek penelitian. Selanjutnya, data sekunder adalah data yang diperoleh melalui penelusuran sumber-sumber tertulis mengenai keberadaan ataupun hasil penelitian terdahulu mengenai gambar cadas di wilayah yang diteliti.

Pengolahan data primer dalam penelitian ini terdiri atas pembuatan peta lokasi situs dan analisis motif gambar. Pembuatan peta lokasi situs diolah dengan metode Geographic 
Information System (GIS) yaitu Arc Map 10.7. Selanjutnya analisis motif gambar dilakukan dengan Software ImageJ dan Adobe Illustrator untuk mempertajam gambar yang sulit diidentifikasi secara langsung. Langkah selanjutnya adalah melakukan klasifikasi. Klasifikasi mengacu pada proses menyusun atau menempatkan objek ke dalam kelompok-kelompok atas dasar pembagian karakteristik tertentu yang disebut atribut (Shearer and Ashmore, 2008: 117).Dalam tahap klasifikasi, digunakan metode klasifikasi taksonomi yang dikemukakan oleh Irving Rouse (1971). Menurutnya, klasifikasi taksonomis memfokuskan pada pencarian berbagai tipe pada data. Tipe itu didapatkan berdasarkan pemilihan atribut yang dimiliki oleh data (Rouse, 1971: 315).

\section{HASIL DAN PEMBAHASAN}

Dari hasil identifikasi diketahui bahwa di Situs Gua Anawai terdapat gambar cadas motif cap tangan sebanyak 100 gambar dengan berbagai bentuk. Oleh karena itu maka dalam bagian ini terlebih dahulu akan diuraikan mengenai Situs Gua Anawai, selanjutnya akan diuraikan klasifikasi motif dan teknik pembuatan motif hewan yang ditemukan.

\section{Situs Gua Anawai}

Secara astronomis situs ini berada pada titik koordinat $3^{\circ} 19 ' 26.01 "$ Lintang Selatan dan 122 04'44.05" Bujur Timur serta berada di ketinggian $42 \mathrm{mdpl}$. Secara geografis situs ini berada di kaki perbukitan karst Matarombeo. Lokasi situs tersebut berada tidak jauh dari ujung salah satu anak sungai Lalindu yakni sekitar $200 \mathrm{~m}$ dari ujung anak sungai. Setelah tiba di ujung anak sungai tersebut, kita masih harus melanjutkan perjalanan menuju lokasi situs yang berada di kaki perbukitan karst yang berlokasi tepat di depan ujung aliran anak sungai dengan lama perjalanan sekitar 10 menit. Perjalanan ditempuh dengan melalui medan yang perlahan menanjak serta melewati bongkahanbongkahan batuan gamping dan rapatnya vegetasi pepohonan. 


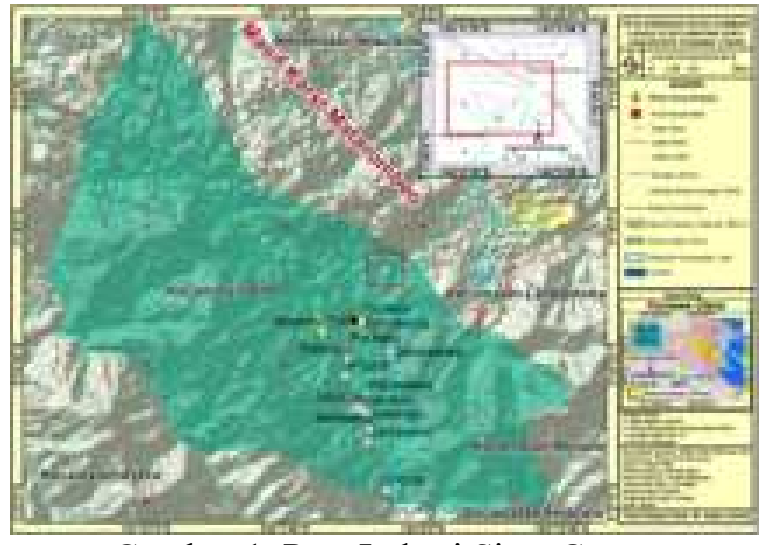

Gambar 1. Peta Lokasi Situs Gua Anawai

Situs Gua Anawai berada berada pada ketinggian $20 \mathrm{~m}$ dari bibir sungai. Vegetasi di sekitar mulut gua cukup rapat dengan pepohonan berukuran cukup besar serta tumbuhan merambat dan rerumputan dengan nama latin Chromolaena Odorata atau dikenal pula dengan nama lokal komba-komba. Intensitas cahaya di dalam ruangan gua cukup baik dengan tingkat kelembabannya pun relatif rendah. Batas-batas geografis dari situs ini adalah di sisi Utara, Timur, dan Barat berbatasan dengan pegunungan karst, di sisi Selatan berbatasan langsung dengan pepohonan. Mulut gua berorientasi ke arah Selatan serta memiliki dimensi ukuran lebar $12 \mathrm{~m}$ dan tinggi langit-langit mulut gua dari permukaan lantai gua mencapai $4 \mathrm{~m}$. Berdasarkan bentuknya, Situs Gua
Anawai merupakan gua horizontal dengan ukuran ruangan yang cukup luas dengan ruangan utama berukuran panjang $18,35 \mathrm{~m}$, lebar $11,88 \mathrm{~m}$ dan tinggi langit-langit gua dari permukaan lantai ruangan yaitu sekitar $4 \mathrm{~m}$.

Berdasarkan hasil observasi, ditemukan berbagai tinggalan arkeologis di situs ini seperti fragmen tembikar dari jenis earthenware dengan beberapa memiliki ragam hias pada permukaannya, fragmenfragmen tulang, perhiasan (diduga sebagai gelang) berbahan cangkang kerang, beberapa cangkang-cangkang moluska dan ratusan gambar cadas dengan berbagai motif. Terkhusus untuk gambar cadas dengan motif cap tangan, diketahui keseluruhan gambar berjumlah 100 gambar yang tersebar di enam panel.

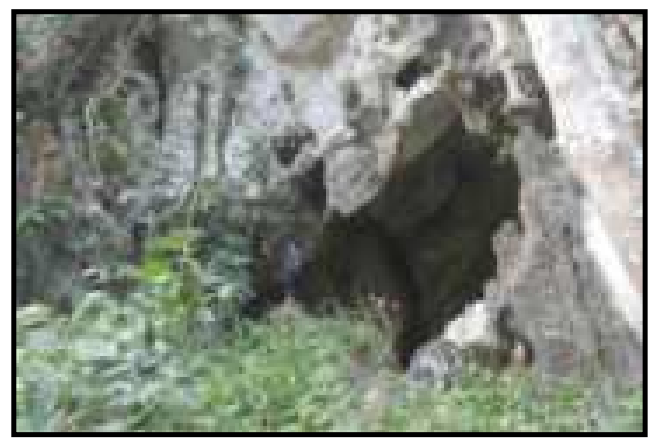




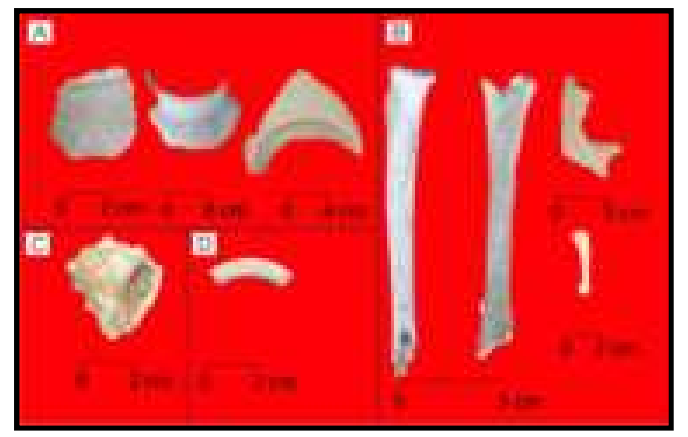

Gambar 2. Mulut Gua Anawai (bawah kiri) dan Temuan Dalam Ruangan Gua Anawai (kanan)

\section{Gambar Cap Tangan}

Gambar cap tangan di Situs Gua Anawai secara keseluruhan ditemukan berjumlah 100 gambar yang tersebar di tujuh panel. Keenam panel tersebut secara keseluruhan terletak di dinding sisi kiri ruangan gua. Panel 1 terletak di dinding sisi utara timur laut dengan orientasi timur tenggara-barat barat laut dan ketinggian rata-rata dasar panel ini dengan teras gua yang berada di bawahnya yaitu $200 \mathrm{~cm}$. Panil ini memiliki ukuran panjang $83 \mathrm{~cm}$ dan lebar $37 \mathrm{~cm}$ serta memiliki gambar cap tangan sebanyak 3 gambar. Panel 2 terletak di dinding sisi Utara Timur Laut dengan orientasi Selatan-Utara. Ketinggian dasar panil ini dengan teras gua yang berada di bawahnya yaitu $200 \mathrm{~cm}$ dengan ukuran panjang panil $163 \mathrm{~cm}$ dan lebar $158 \mathrm{~cm}$.
Jumlah gambar cap tangan di panel ini berjumlah 12 gambar. Panel 3 terletak di dinding sisi utara timur laut ruangan gua dengan orientasi selatan tenggara-utara barat laut tepatnya di sisi kanan bawah panil 2. Panil ini berada di ketinggian $113 \mathrm{~cm}$ dari teras gua yang berada di bawahnya. Secara bentuk panil ini merupakan sebuah bidang dengan yang berbentuk cekungan dengan diameter $54 \mathrm{~cm}$. jumlah gambar cap tangan dari panel ini berjumlah 8 gambar. Panil 4 terletak di dinding ruangan sisi timur laut ruangan gua dengan orientasi barat daya-timur laut tepatnya berada di sisi kanan atas dari panil 3. Panil ini berada di ketinggian $125 \mathrm{~cm}$ dari teras ruangan yang berada di bawahnya. Ukuran dari panil ini adalah memiliki panjang $117 \mathrm{~cm}$ dan lebar $104 \mathrm{~cm}$. Gambar cap tangan yang ditemukan di panel ini berjumlah 4 gambar. Panil 5 terletak di dinding sisi Timur timur laut dari ruangan Situs Gua Anawai dengan orientasi selatan barat dayautara timur laut pada ketinggian 90 $\mathrm{cm}$ dari teras gua yang berada di bawahnya. Panil ini erada di sisi kiri panil 5 dengan bentuk persegi panjang kearah langit-langit gua. 
Panil ini memiliki ukuran panjang $190 \mathrm{~cm}$ dan lebar $107 \mathrm{~cm}$. Gambar cap tangan di panel ini berjumlah 23 gambar. Panil 6 terletak di dinding sisi Timur Timur laut ruangan gua dengan orientasi selatan tenggarautara barat laut pada ketinggian $60 \mathrm{~cm}$ dari teras gua yang berada di bawahnya. Panil ini memiliki ukuran panjang $89 \mathrm{~cm}$ dan lebar $74 \mathrm{~cm}$. Jumah gambar cap tangan dari panel ini yaitu sebanyak 37 gambar. dimiliki oleh masing-masing gambar. Dengan demikian, penentuan atribut dalam tahap ini dilakukan dengan melihat aspek mendasar dasar dari sebuah motif.

Dalam klasifikasi taksonomi, dikenal beberapa istilah seperti "kategori”, “tipe", "subtipe", "subsubtipe" dan "varian". Kategori merupakan sebuah sistem dalam klasifikasi yang merupakan

\section{Analisis Bentuk}

penggolongan satuan alat

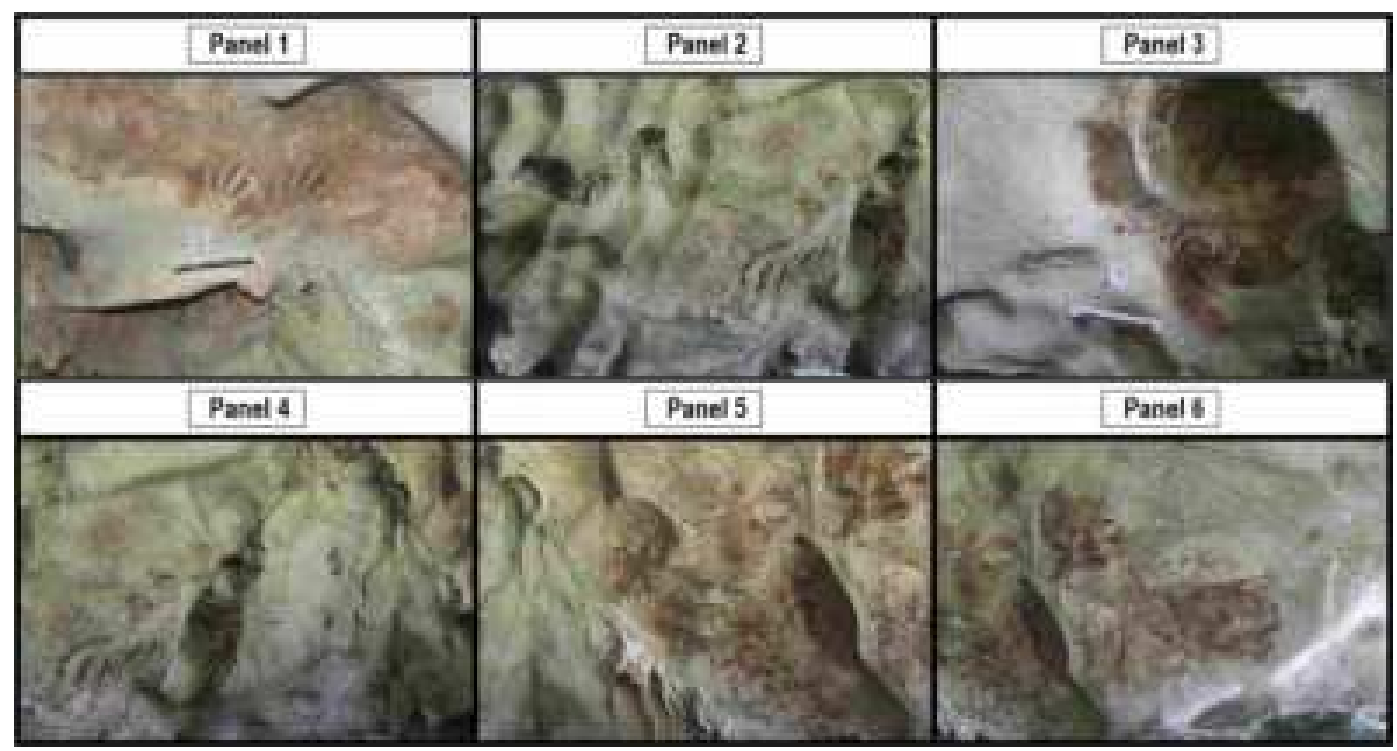

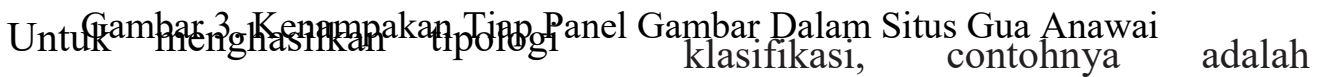
bentuk motif cap tangan dalam penelitian ini, terlebih dahulu dilakukan pengelompokkan gambar berdasarkan persamaan atau perbedaan dari atribut kuat yang klasifikasi motif tangan. "Kategori 1" merupakan atribut bentuk yang bersifat umum pada motif tangan yang dijadikan satuan "tipe", yaitu (T1) telapak tangan, (T2) telapak 
sampai pergelangan, telapak sampai lengan (T3) dan telapak tangan rusak (T4). Mengingat kemungkinan perbedaan sisi tangan di setiap bentuk, atribut sisi tangan dijadikan kategori 2" yang merupakan satuan yaitu (1) lengkap, (2) kurang dan (3) rusak. Perlu ditekankan bahwa keempat kategori atribut tersebut mengacu pada atribut telapak tangan yang dikemukakan oleh Permana (2014). Berikut skema klasifikasi taksonomi yang digunakan dalam

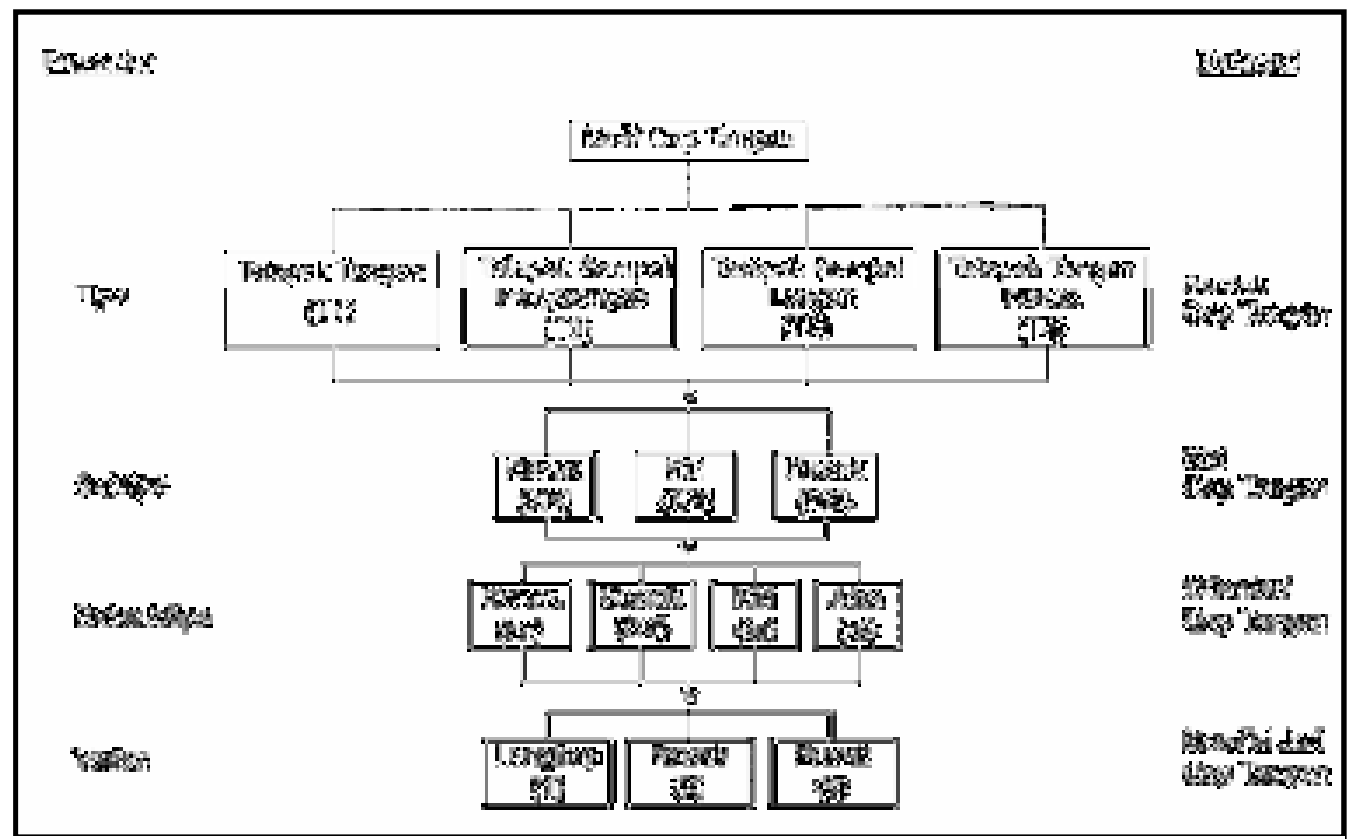

Gambar 4. Skema Klasifikasi gambar Cap Tangan di Situs Gua Anawai

subtipe, yaitu (KN) kanan, (KR) kiri dan rusak (RS). Selanjutnya, adalah "kategori 3" yang merupakan atribut arah hadap atau orientasi yang merupakan "kategori 3" yang terdiri atas satuan "subsubtipe" (at) atas, (kn) kanan, (bw) bawah, dan (kr) kiri. sementara atribut terakhir adalah kenampakan jari dari motif tangan yang merupakan satuan dari "varian”,
- Atribut 1 (bentuk cap tangan)

Atribut ini mengacu pada bentuk umum dari motif cap tangan yang ditemukan. Adapun bentuk tersebut yaitu bentuk telapak tangan (T1), Telapak Tangan sampai pergelangan (T2), Telapak Tangan sampai Lengan (T3) dan Telapak tangan rusak (T4). 


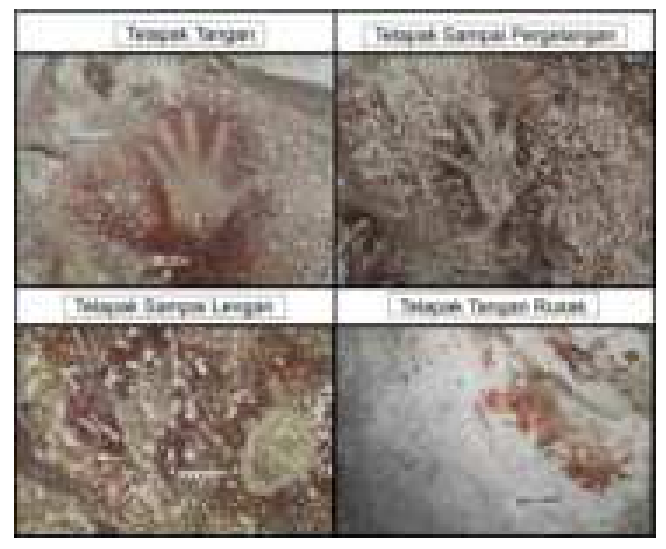

Gambar 5. Atribut Bentuk Motif Cap Tangan

- Atribut 2 (sisi cap tangan)

Atribut ini mengacu pada sisi tangan yang digambarkan. Sisi tangan yang dimaksud adalah sisi kiri (KR), kanan (KN) dan rusak (RS).

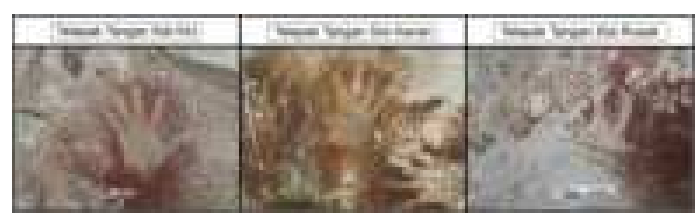

Gambar 6. Atribut Sisis Motif Cap Tangan

- Atribut 3 (orientasi cap tangan) Atribut ini mengacu pada orientasi dari gambar motif cap tangan yang ditemukan. Orientasi yang dimaksudkan terdiri atas kanan $(\mathrm{KN})$, bawah (BW), kiri (KR) dan atas (AT).

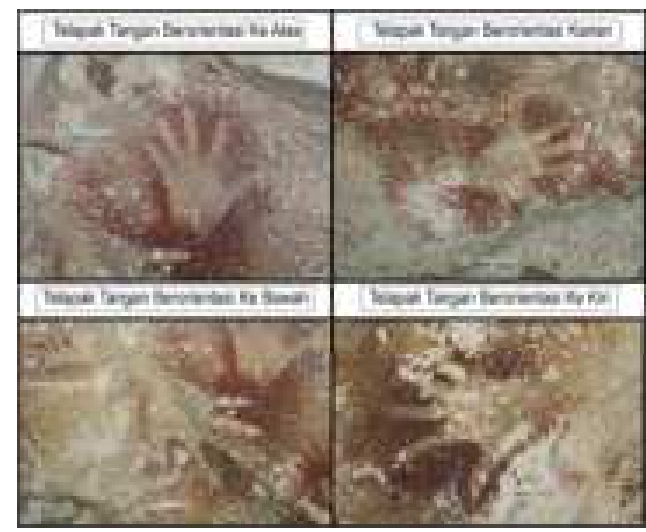

Gambar 7. Atribut Orientasi Motif Cap Tangan

- Atribut 4 (kondisi jari cap tangan)

Atribut ini mengacu pada kondisi dari jari yang tampak pada gambar motif cap tangan. Kondisi tersebut di antaranya lengkap (1), tidak lengkap (2) dan rusak (3).

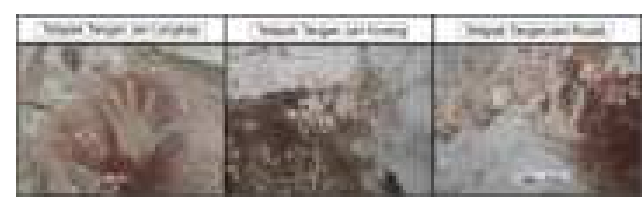

Gambar 8. Atribut Kenampakan Jari Motif Cap Tangan

\section{Tipologi Motif Cap Tangan di}

\section{Situs Gua Anawai}

Berdasarkan hasil identifikasi dengan menerapkan skema klasifikasi yang diajukan oleh Permana (2014), maka diketahui tipologi pada gambar cadas cap tangan di Situs Gua Anawai bentuk yang sangat beragam. Untuk mengetahui bentuk-bentuk dari motif cap tangan tersebut maka akan 
diuraikan tabel yang tertuang di bawah ini:

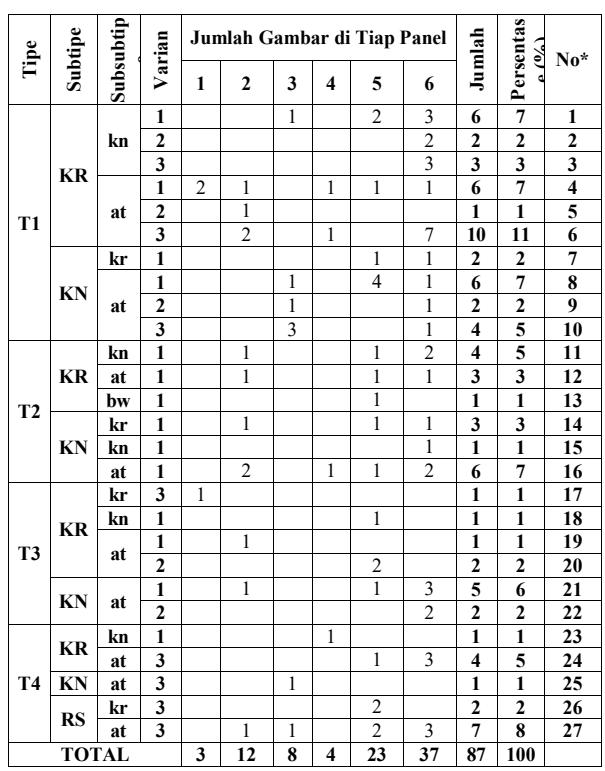

*Dari 100 gambar cadas cap tangan di Gua Anawai setelah dilakukan klasifikasi taksonomi didapatkan 27 bentuk motif cap tangan

Tabel 1. Persentase Tiap Bentuk Motif Cap Tangan Di Situs Gua Anawai

Berdasarkan tabel di atas, dapat diketahui bahwa 4 tipe dasar dari motif cap tangan di Situs Gua Anawai. Keempat tipe tersebut yaitu: pertama motif telapak tangan (T1), kedua motif telapak tangan sampai pergelangan (T2), ketiga motif telapak tangan sampai lengan (T3) dan keempat motif telapak tangan rusak (T4). Masing-masing tipe tersebut memiliki jumlah yang beragam. Berikut uraian dari keempat tipe tersebut:
- Tipe 1 (Motif Telapak Tangan (T1))

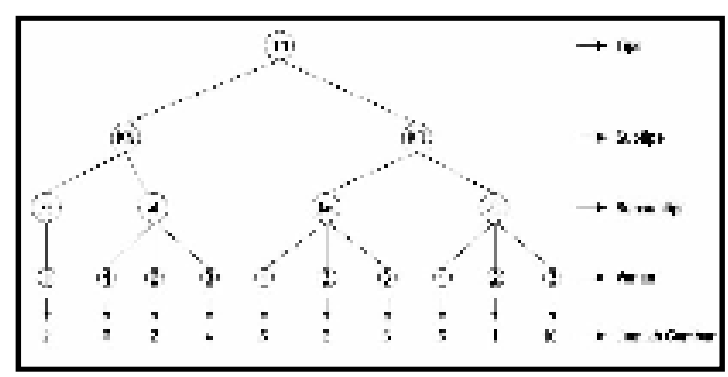

Gambar 9. Tipologi Motif Cap Tangan Tipe $\mathbf{T 1}$

Motif cap tangan dari tipe telapak tangan (T1) terdiri dari 10 bentuk motif cap tangan yaitu bentuk

T1KNkr1，T1KNat1，T1KNat2, T1KNat3，T1KRkn1，T1KRkn2, T1KRkn3, T1KRat1, T1KRat2 dan bentuk T1KRat3. Dari tipe ini diketahui motif telapak tangan sisi kanan berjumlah 10 gambar dan motif telapak tangan sisi kiri berjumlah 8 gambar. Dengan demikian terdapat 18 gambar cap tangan dari tipe $\mathbf{T} \mathbf{1}$.

- Tipe 2 (Motif Telapak Tangan Sampai Pergelangan (T2))

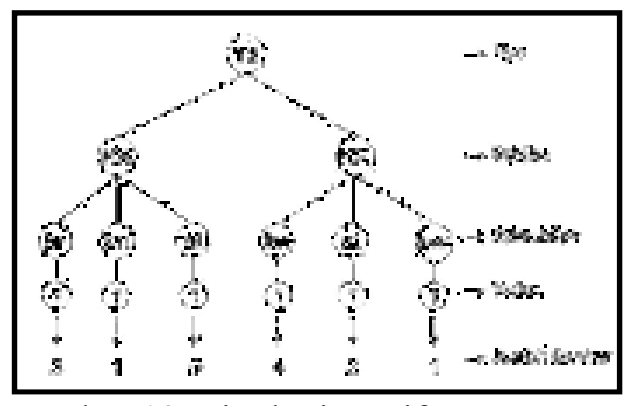

Gambar 10. Tipologi Motif Cap Tangan Tipe $\mathbf{T} 2$ 
Motif cap tangan dari tipe telapak tangan sampai pergelangan (T2) terdiri dari 6 bentuk motif yaitu bentuk T2KNkr1, T2KNkn1, T2KNat11，T2KRkn1， T2KRat1 dan bentuk T2KRbw1. Jumlah motif cap tangan sisi kanan dari tipe ini berjumlah 13 gambar dan motif cap tangan sisi kiri berjumlah 9 gambar. Dengan demikian jumlah keseluruhan motif cap tangan dari tipe yaitu sebanyak 22 gambar.

- Tipe 3 (Motif Telapak Tangan Sampai Lengan (T3))

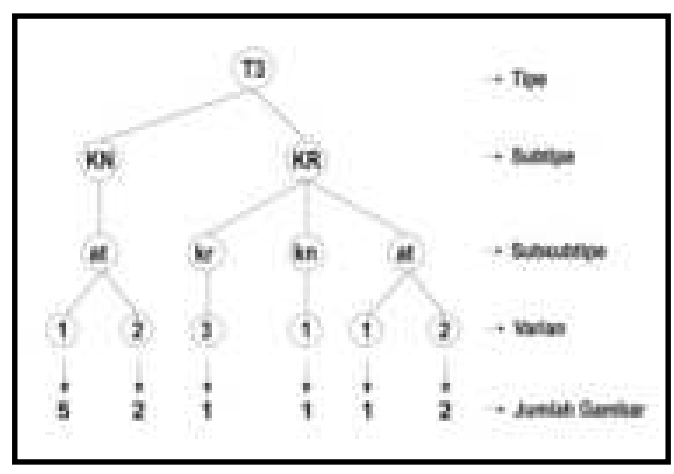

Gambar 11. Tipologi Motif Cap Tangan Tipe $\mathbf{T 3}$

Motif cap tangan dari tipe telapak tangan sampai lengan (T3) terdiri dari 6 bentuk motif yaitubentuk T3KNat1，T3KNat2， T3KRkr3, T3KRkn1，T3KRat1, dan bentuk T3KRat2. Jumlah motif cap tangan sisi kanan dari tipe ini berjumlah 7 gambar dan motif cap tangan sisi kiri berjumlah 5 gambar. Dengan demikian jumlah keseluruhan motif cap tangan dari tipe T3 yaitu sebanyak 12 gambar.

- Tipe 4 (Motif Telapak Tangan Rusak (T4))

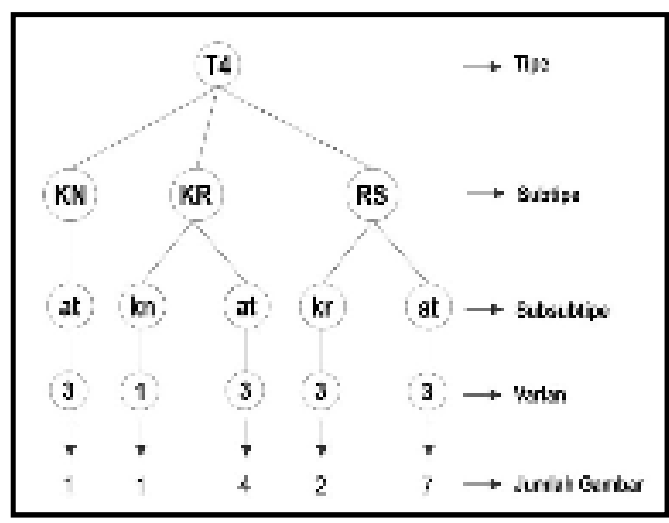

Gambar 12. Tipologi Motif Cap Tangan Tipe T4

Motif cap tangan dari tipe telapak tangan rusak (T4) terdiri dari 5 bentuk motif yaitu bentuk T4KNat3, T4KRkn1, T4KRat3, T4RSkr3 dan bentuk T4RSat3. Jumlah motif cap tangan sisi kanan dari tipe ini berjumlah 1 gambar, motif cap tangan sisi kiri berjumlah 5 gambar, sementara motif cap tangan yang tidak diketahui sisinya berjumlah 7 gambar. Adapun jumlah keseluruhan motif cap tangan dari tipe $\mathbf{T} 4$ yaitu sebanyak 15 gambar. Apabila keseluruhan hasil tipologi gambar cadas cap tangan (tipe T1 - T4) 
digabungkan menjadi satu skema taksonomi akan menghasilkan skema dendrogram sebagai berikut:
T4RSat3. Selanjutnya, dari keempat tipe dasar gambar yang ditemukan diketahui tipe telapak tangan (T1)

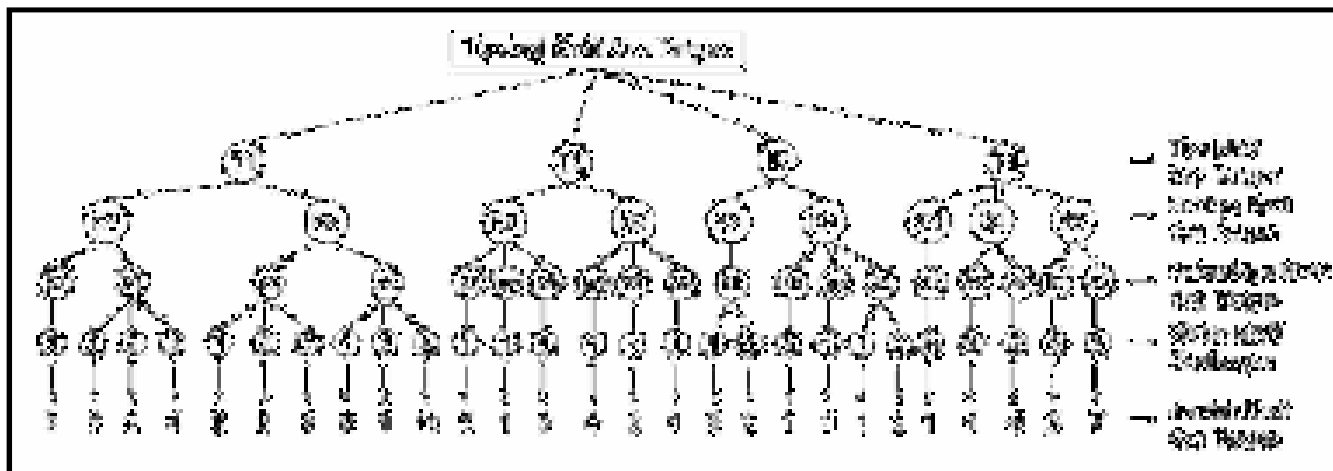

Gambar 12. Tipologi Motif Cap Tangan di Situs Gua Anawai

\section{SIMPULAN}

Dari hasil penelitian yang dilakukan, diketahui bahwa di Situs Gua Anawai terdapat berbagai bentuk motif cap tangan. Dari 100 gambar yang telah diklasifikasi dari keseluruhan gambar motif cap tangan yang ditemukan diketahui berjumlah 27 bentuk yang terdiri atas bentuk T1KNkr1，T1KNat1，T1KNat2, T1KNat3，T1KRkn1，T1KRkn2, T1KRkn3， T1KRat1， T1KRat2, T1KRat3，T2KNkr1，T2KNkn1, T2KNat11，T2KRkn1，T2KRat1, T2KRbw1，T3KNat1，T3KNat2, T3KRkr3，T3KRkn1， T3KRat1, T3KRat2, T4KNat3, T4KRkn1, T4KRat3, T4RSkr3 dan bentuk merupakan tipe motif cap tangan yang paling mendominasi dengan jumlah gambar sebanyak 42 gambar. Sementara tipe cap tangan yang ditemukan dengan jumlah gambar terendah berasal dari tipe telapak tangan hingga lengan (T3) dengan jumlah gambar sebanyak 12 gambar.

Perbedaan jumlah gambar dari tiap tipe tersebut menunjukkan perbandingan jumlah gambar yang lebih dominan dari tipe yang lain. Dalam memahami fenomena tersebut, faktor usia dari gambar tersebut dan berbagai kerusakan yang telah terjadi pada gambar-gambar tersebut tidak dapat dikesampingkan. Kemungkinan kerusakan pada gambar yang menyebabkan hilangnya 
gambar bisa saja terjadi. Namun, perbedaan yang cukup besar terhadap persentase dari tiap tipe tersebut yang masih dapat kita saksikan hingga saat ini mungkin memang telah terjadi dan lahir sebagai produk budaya yang memiliki arti tersendiri. Merujuk pada pandangan yang diberikan oleh Permana (2014), menurutnya kehadiran bentuk gambar yang ditemukan dengan jumlah yang lebih sedikit diperkirakan memiliki arti tersendiri (Permana, 2014: 288).

\section{DAFTAR PUSTAKA}

Duli, Akin dan Muhammad Nur. 2016. Prasejarah Sulawesi. Makassar: Fakultas Ilmu Budaya Universitas Hasanuddin.

Fage, L.H. 2014. Matarombeo 2014. Natur Evolution.

Leihitu, Irsyad. 2016. Tipologi Motif Cap Tangan Prasejarah di Leang Uhalie, Kabupaten Bone, Sulawesi Selatan. Paradigma Jurnal Kajian Budaya. Vol.6. No.2. hal 207-218.

Mulyadi, Yadi. 2016. "Distribusi dan Sebaran Situs Gambar Cadas di Indonesia: Sintesis Penelitian". Makalah Dalam Seminar Internasional Arkeologi, Sejarah, Bahasa, dan Budaya di Alam Melayu (ASBAM) Ke-5 di Makassar. 26-27 Juli 2016.

Nipa, R.L.A.O. 2018. Identifikasi Gambar Cadas Pada Situs Gua Pondoa Di Desa Pondoa Kecamatan Wiwirano Kabupaten Konawe Utara. Skripsi. Kendari: Universitas Halu Oleo. Tidak Terbit.

Noerwidi, Sofwan. 2008. Mengarungi Garis Wallacea: Awal Migrasi Manusia dari Paparan Sunda Menuju Kawasan Wallace. Berkala Arkeologi Tahun XXVIII Edisi No. 2. Yogyakarta: Balai Arkeologi Yogyakarta 
Noerwidi, Sofwan. 2014. Migrasi Austronesia dan Implikasinya Terhadap Perkembangan Kebudayaan di Indonesia. Amerta Jurnal Penelitian dan Pengembangan Arkeologi. Vol: 32 No: 1.

Oktaviana, A.A dkk. 2016. "Hand Stencil With And Without Narrowed Fingers At Two New Rock Art Sites In Sulawesi, Indonesia".Rock Art Research. Vol. 33. Proquest. hlm. 71-88.

Permana. R.C.E. 2014. Gambar Tangan Gua-gua Prasejarah Pangkep-Maros Sulawesi Selatan. Jakarta: Wedatama Widya Sastra.

Rouse, Irving. 1971. "The Classifications Of Artifacts In Archaeology". Dalam Lyman, R. L. dkk, (Editor). Americanist Culture History: Fundamental of Time, Space, and Form. New York: Plenum Press.

Sharer, R.J. dan Wendy, A. 2003. Archaeology Discovering Our Past. New York: McGraw-Hill Companies.

Usman, S.M, dkk 2020. Gambar cadas Situs Kompleks Ceruk Waburi di Desa Gaya Baru, Kecamatan Lapandewa, Kabupaten Buton Selatan. Sangia. Vol.4. No.1. hal. 13-25

Whitley, D.S. 2005. Introduction To Rock Art Research. California: Left Coast Press Inc. 